\title{
Efficacy and Safety of Long-Pulsed Nd-Yag Laser in Treatment of Hirsutism
}

Rosie $\mathrm{TN}^{1}$, Khan MAL ${ }^{2}$, Khan $\mathrm{MSl}^{3}$, Yazdi QS ${ }^{4}$, Karim ATMR ${ }^{5}$

DOI: https://doi.org/10.3329/jafmc.v14i2.45901

\begin{abstract}
Introduction: Hirsutism is a condition of unwanted malepattern hair growth in women. Perception of hirsutism is subjective and it is a common condition affecting $5-10 \%$ of unselected women.
\end{abstract}

Objectives: To find out the efficacy and safety of long-pulsed Nd-YAG laser in the treatment of hirsutism.

Materials and Methods: Fifty females of age between 1850 years with dark terminal facial hair and normal hormonal profile were treated with long-pulsed Nd-YAG laser (1064nm, $10 \mathrm{~mm}$ spot size, pulse duration of 25-30 minutes and fluence of $25-40 \mathrm{~J} / \mathrm{cm}^{2}$ ). Six consecutive sessions of laser treatment were delivered to all the patients at 4 to 6 weeks' interval. Photographic evaluations and percentage of hair reduction were done before each session and final assessment noted at the end ofninemonths.

Results: All the patients completed the study. Good hair reduction (50-75\%) was seen in $52 \%$ of patients after the first treatment session. After six consecutive treatment sessions at the end of nine-month excellent hair reduction (>75\%) was noted in $86 \%$ of patients and good hair reduction $(50-75 \%)$ seen in $12 \%$ patients. Side effects in our study were post-operative erythema in $40 \%$ and perifollicular oedema in $33.33 \%$.

Conclusion: The study supportslong-pulsed Nd-YAG laser with multiple six sessionsis safe and effective in the treatment of hirsutism.

Key-words: Hirsutism, Nd-YAG laser, Hair reduction.

\section{Introduction}

Hirsutism is defined as excessive terminal hair in a female in male pattern distribution ${ }^{1}$. It affects $5-10 \%$ of women and is a common presenting complaint in the dermatological outpatient department for cosmetic reasons ${ }^{2}$. Hirsutism may be idiopathic or secondary to increased responsiveness of hair follicles to a normal circulating level of androgens, or it may result from an excess of androgens or other hormones ${ }^{3}$. Classically hirsutism can be considered as a marker of increased androgen levels in females from increased production of androgens either by adrenal or due to ovarian disease. The ovarian causes for hyperandrogenism are polycystic ovarian syndrome, ovarian tumour and adrenal causes include Cushing's syndrome, androgen producing tumours and congenital adrenal hyperplasia. Androgenic drugs also an important cause of hirsutism². The treatment depends on the cause of hirsutism. Treatment of hirsute women with idiopathic hirsutism should be cosmetic ${ }^{4}$.Various medical and dermatocosmetic treatment options are available for the hirsutism. Dermatocosmetic options are hair bleaching, shaving, depilation with tweezers and waxing. Electrolysis, as well as lasers and light source epiliation, are available methods for definite depilation ${ }^{5}$. Laser hair removal has obtained broad clinical acceptance in both medical and aesthetic settings because of its invasive in nature, long term result, minimal treatment discomfort, and speed and ease with which procedure can be performed ${ }^{6}$.

The lasertargets the melanin present in the hair follicle based on the theory of selective photothermolysis and leads to the destruction of hair follicle. Lasers emitting light in the wave length range of 600 to $1100 \mathrm{~nm}$ can specifically target the melanin in the entire portion of hair follicles ${ }^{7}$. Patient with dark hair and lightly pigmented skin are the best candidates for laser hair reduction treatment. In contrast, white, blond and grey hairs generally respond poorly given their absence of a sufficient pigment target ${ }^{8}$. Different Laser systems and intense pulse-light have been currently approved by the Food and Drug Administration for the reduction of hair include long-pulsed Ruby $(694 \mathrm{~nm})$, alexandrite $(755 \mathrm{~nm})$, diode $(800 \mathrm{~nm})$ and $\mathrm{Nd}-$ YAG (Neodymium-doped yttrium aluminium garnet) (1064nm) lasers and IPL (500 to $1200 \mathrm{~nm})$ sources $^{9}$. Shorter wavelength laser has more superficial epidermal penetration and therefore increased risk for epidermal melanin absorption and injury to surrounding skin and usually avoided in patients with darker skin types ${ }^{10}$. Nd-YAG laser has a longer wave length and provides deeper epidermal penetration so that even deep-lying follicles receive enough energy for epilation and there is also very little epidermal absorption making the device well suited for dark skin ${ }^{11}$. Female hirsutism is an embarrassing condition

1. Lt Col. Tawhida Nawazesh Rosie, MBBS, DDV, FCPS, Classified Specialist in Dermatology, Prime Minister's Office, Dhaka (E-mail: tawhidarosie124@gmail.com) 2. Brig Gen Md Abdul Latif Khan, MBBS, DDV, FCPS, Classified Specialist in Dermatology, Adviser Specialist in Dermatology CMH, Dhaka 3. Col Md Shirazul Islam Khan, MBBS, MCPS, DDV, FCPS, Classified Specialist in Dermatology, CMH, Dhaka 4. Lt Col Quazi Salim Yazdi, MBBS, DDV,FCPS, Classified Specialist in Dermatology, CMH, Dhaka 5. Lt Col ATM Rezaul Karim, MBBS, MCPS, DDV, FCPS, Associate Professor \& Head, Department of Dermatology, AFMC, Dhaka. 
that threatened both a woman's perception of femininity and her self-esteem, for this reason various methods of hair removal have been practice ${ }^{12}$. Lasers have revolutionized the treatment of unwanted hair. Laser-assisted reduction offers efficient and swift option for hair reduction as compared to other available modalities such as waxing, shaving and electrolysis ${ }^{13}$. There have been remarkable advances in laser hair removal with different type of available lasers in the market ${ }^{14}$. Every laser system has some advantages and disadvantages regarding reduction of hairs, side effects, compliance etc. In past few years long-pulsed Nd-YAG laser has appeared as an effective hair removal system with few side effects ${ }^{15}$.

The outcome of laser hair reduction depends on many factors including the types of laser which differ in wave length, pulse duration, fluence, laser-beam delivery system, number of treatment sessions and also patient's skin type and nature of the hair follicles. The purpose of this study was to find out the efficacy and safety of long-pulsedNd-YAG laser for the treatment of hirsutism with six consecutive laser sessions in darker skin phototype.

\section{Materials and Methods}

This was a prospective clinical trial done in the Department of Dermatology and Venereology, Combined Military Hospital, Dhaka Cantonment from January 2017 to December 2017. The study group composed of 50 female patients with hirsutism aged between 18 to 50 years. All patients had a thorough clinical examination and their skin type noted according to the Fitzpatrick scale. All the relevant details regarding age, sites of involvement, treatment history and associated disorders were recorded on a specially designed format. Hormonal assays including follicle stimulating hormone, luteinizing hormone, serum androgens, serum prolactin and abdominopelvic ultrasonography were done to exclude any hormonal abnormality.

Patients with dark pigmented hair restricted to face only and normal hormonal profile were included in the study.Patient having hypertrichosis, keloid tendency, taking photosensitive drugs, photosensitivity or with laser treatment or electrolysis to study area in the previous six months were excluded from the study. Patients were treated with a long-pulsed Nd-YAG laser $(1064 \mathrm{~nm}$, with a spot size of $10 \mathrm{~mm}$, pulse duration of 25 30 minutes and fluence of $\left.25-40 \mathrm{~J} / \mathrm{cm}^{2}\right)$. Six consecutive laser treatments delivered to all patients at 4 to 6 weeks' interval. Photographic evaluations were obtained at baseline, before each treatment session and final assessment was done at 9th month. Percentage of hair reduction was determined by subjective assessment of hair count and noted before each treatment session. Percentage of hair reduction was graded as excellent (>75\%), good (50-75\%), fair (25-49\%) and poor $(<25 \%)$. Patients were examined for any immediate or late side effects and final assessment was done at 9th month.

\section{Results}

The study included fifty female patients suffering from hirsutism in the agerange from 18 to 50 years. Most of the patients were in the age group of 21-30 years. A majority $(60 \%)$ of the patients were skin phototype $1 \mathrm{~V}$, followed by skin phototype III (18\%) and none of the patients was of skin phototype I, II and VI (Table-I). Sixteen patients (32\%) had involvement of full-face whereas only upper lip is involved in twelve $(24 \%)$ patients. Fourteen patients $(28 \%)$ had involved hair growth both in lip and chin. Two patients (4\%) had chin involvement exclusively and hirsutism was restricted to beard area in six patients (12\%). Average hair reduction at 4 weeks $45.26 \%$, at 8 weeks $63.26 \%$ at 12 weeks $69.33 \%$ and at 9th month $76.06 \%$ (Table -II). At 4 weeks; $26(52 \%)$ patients had good and $18(36 \%)$ patients had fair hair reduction. At 8 weeks; 16(32\%) patients had excellent, 27(54\%) had good and $7(14 \%)$ patients had fair hair reduction. At 12 weeks; $31(62 \%)$ patients had excellent, $15(30 \%)$ had good and $4(8 \%)$ patients had fair hair reduction. At the end of nine months and after six consecutive laser sessions, $43(86 \%)$ patients had excellent, $6(12 \%)$ patients had good and $1(2 \%)$ patienthad fair hair reduction (Table-III). Erythema, perifollicular oedema and hyper pigmentation were the adverse effects noted. Short term erythema was seen in $40 \%$ patients, perifollicular oedema in $33.33 \%$ and post-inflammatory hyperpigmentation were seen in $12 \%$ cases. No incidence of any scar, crusting or blistering.

Table-I: Distribution of patients by skin phototype $(n=50)$

\begin{tabular}{|c|l|l|c|c|}
\hline $\begin{array}{c}\text { Skin } \\
\text { Phototype }\end{array}$ & \multicolumn{1}{|c|}{ Skin Color } & Hair Color & Frequency & Percentage \\
\hline III & $\begin{array}{l}\text { Light Brown/ } \\
\text { Asian }\end{array}$ & $\begin{array}{l}\text { Dark Blond, } \\
\text { Light Brown }\end{array}$ & 9 & 18 \\
\hline IV & $\begin{array}{l}\text { Moderate Brown/ } \\
\text { Asian }\end{array}$ & $\begin{array}{l}\text { Light Brown, } \\
\text { Brown, Black }\end{array}$ & 30 & 60 \\
\hline V & $\begin{array}{l}\text { Dark Brown/ } \\
\text { Indian }\end{array}$ & $\begin{array}{l}\text { Dark Brown, } \\
\text { Black }\end{array}$ & 11 & 22 \\
\hline
\end{tabular}

Table-II: Distribution of patients byaverage hair reduction $(n=50)$

\begin{tabular}{|l|c|}
\hline \multicolumn{1}{|c|}{ Time } & Percentage of hair reduction \\
\hline 4 week & 45.26 \\
\hline 8 week & 63.26 \\
\hline 12 week & 69.33 \\
\hline 16week & 70.11 \\
\hline 20 week & 72.22 \\
\hline 9th month & 76.06 \\
\hline
\end{tabular}

Table-III: Distribution of patients on the basis of response at different time interval $(n=50)$

\begin{tabular}{|c|c|c|c|c|}
\hline Time at & Excellent $\%$ & Good $\%$ & Fair $\%$ & Poor $\%$ \\
\hline 4 weeks & 0 & $26(52)$ & $18(36)$ & $6(12)$ \\
\hline 8 weeks & $16(32)$ & $27(54)$ & $7(14)$ & 0 \\
\hline 12 weeks & $31(62)$ & $15(30)$ & $4(8)$ & 0 \\
\hline 16 weeks & $36(72)$ & $12(24)$ & $2(4)$ & 0 \\
\hline 20 weeks & $39(78)$ & $10(20)$ & $1(2)$ & 0 \\
\hline 9thmonth & $43(86)$ & $6(12)$ & $1(2)$ & 0 \\
\hline
\end{tabular}

*Percentage in parenthesis 


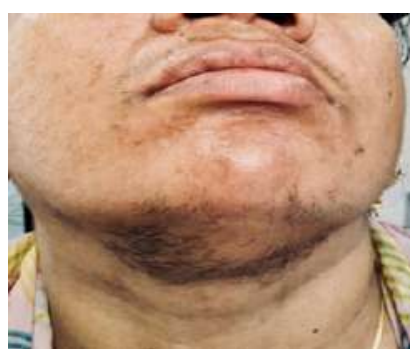

Figure-1a: Chin at first visit

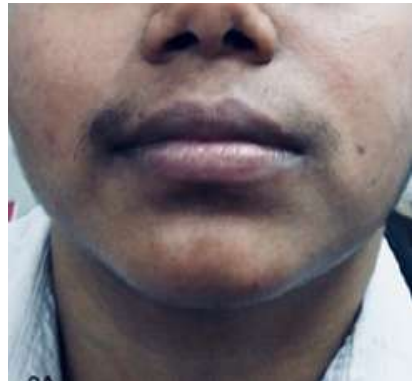

Figure-2a: Upper lip at first visit

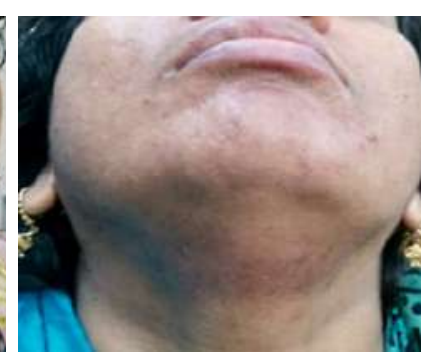

Figure-1b: Chin after 9 months

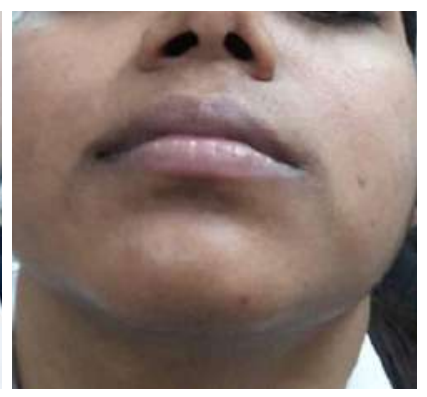

Figure-2b: Upper lip after 9 month

\section{Discussion}

The findings of this study showed that the long-pulsed Nd-YAG Laser is safe and effective up to six multiple sessions in darker skin type. Most of the patients in this study group belonged to the age group of 18-30 years. Similar age incidence was observed by Neerja Puri ${ }^{16}$ where thirty patients had hirsutism and $50 \%$ patients were between $21-30$ years of age. In this study, at the end of 4 weeks, good hair reduction was noted in $52 \%$ patients, which is similar to the hair reduction obtained ofother studies ${ }^{17,18}$; where after one month $50 \%$ patients showed good hair reduction. In this study at the end of 8 weeks, excellent hair reduction was noted in $32 \%$ and good in $54 \%$ patients and at 12 weeks, excellent hair reduction was noted in $62 \%$ and good $30 \%$ patients. After a series of six treatment session at the end of nine months, excellent hair reduction was noted in $86 \%$ and good in $12 \%$ patients. Similar incidence was noted in study by Shrimal and Sardar ${ }^{17}$ where excellent hair reduction of $93.33 \%$ was observed after six sessions. Tanzi and Alster ${ }^{19}$ found a mean hair reduction of $41-46 \%$ on the face after 6 months of a three treatment sessions longpulsed Nd-YAG laser. In another study conducted by Noor and Paracaha ${ }^{3}$, demonstrated a mean hair reduction of $65 \%$ on the face at six months, after a series of four long-pulsed Nd-YAG laser treatment. Neerja puri ${ }^{16}$ in noted that after four sessions of treatment hair reduction was $62 \%$ with $\mathrm{Nd}$ YAG laser. Goldberg and Silapunt ${ }^{20}$ achieved hair reduction of $26-29 \%$ at various sites other than face such as axilla and bikini that were treated with long-pulsed Nd-YAG laser. In this study, multiple treatment sessions were given in patients with hirsutism involving the face only and who had no underlying hormonal problem and had darkhair. These were major factors in achieving better result in compared to other studies in which $\mathrm{Nd}$-YAG laser was used for hair reduction.
Multiple sessions undoubtedly yield more effective result because ofthe target of laser only the anagen or active phase of hair growth cycle. At any given time, nearly $50-65 \%$ of facial hair is in the anagen phase for period of 3 to 4 weeks. Therefore, even if $100 \%$ of all anagen hairs are dilapidated after each treatment only a percentage of total hair would be removed. The same holds true for each consecutive treatment and hence, multiple treatment sessions are required to attain the best case scenario ${ }^{21}$. In this study, side effects noted were post-procedure erythema in $40 \%$ patients, perifollicular oedemain $33.33 \%$ and post-inflammatory hyperpigmentation in $12 \%$ cases. Mittal and Sriram et a ${ }^{21}$ noted mild to moderate pain in $100 \%$ of treatment sites, short term erythema in $90 \%$, perifollicular oedema in $80 \%$ and blistering in $0.8 \%$ of patients. Noor and Paracaha ${ }^{3}$ noted that $95 \%$ patient showed erythema, $89 \%$ of patients had perifollicular oedema and hyperpigmentation was seenin $2 \%$ patients with long-pulsed Nd-YAG laser for hair removal. The side effects observed in this study are less, transient and self-limiting thus establishing the fact that long-pulsed Nd-YAG laseris a safe modality for hair removal.

The long-pulsed Nd-YAG laser is the safest laser for hair removal in darker skin type. Two factors favour the safety of long-pulsed Nd-YAG in darker skin type. Firstly, the Nd-YAG laser has a wave length of $1064 \mathrm{~nm}$ which is at the end of the absorption spectrum of melanin. This wave length is sufficient to attain significant thermal injury in dark coarse hairs while sparing epidermal pigment ${ }^{16.20}$. Secondly, the adjustable pulse with of long-pulsed Nd-YAG laser allows the laser energy to be delivered over a prolonged period of time allowing for the heat to dissipate and sufficient epidermal cooling to occur ${ }^{14,19}$. The long-pulsed Nd-YAG laser is receiving the most attention at this long wave length of light. At this wave length of light melanin absorption is decreased, which require higher fluences to destroy the hair effectively. Epidermal cooling devices incorporated into these devices assure a reduction in the potential for epidermal injury and allow them to successfully use in patient with dark skin type $\mathrm{V}^{21}$.

\section{Conclusion}

The results of this study support effective and safe use of six consecutive laser sessions with long-pulsed Nd-YAG laser for hair removal in Bangladeshi patient with darker skin phototype. The effectiveness of laser sessions was directly dependent upon the number of sessions. Side effects were minimal and self-limiting.

\section{References}

1. Hughes CL. Hirsutism. In Olsen EA, editor. Disorder of Hair growth. New York; Mc Graw- Hill 2003:431-52.

2. Siloni Sachdeva. Hirsutism: Evaluation and Treatment. Indian J. Dematol 2010; 55(1):3-7.

3. Noor SM, Paracaha MM. Effectiveness of Long Pulsed Nd:YAG laser in Hair Removal. JPML 2010; 24(3):198-201. 
4. Loriaux, D. Lynn. An approach to the patient with Hirsutism. Obstetrical \& Gynecological Survey 2013; 68(1):39-41.

5. Liew SH. Unwanted body hair and its removal: A review. Dermatol Surg 1999; 25:431-9.

6.Goldberg DJ. Intense pulsed light. Laser hair removal. London: Martin Dunitz 2000:149-75.

7. Sadick NS, MakinoY. Selective electro-thermolysis in aesthetic medicine: A review. Lasers Surg Med 2004; 34:91-7.

8. James WD, BergerT G. Elston (eds). Andrews' Diseses of the Skin. 12 ed. China: Elsevier 2016:910.

9. Haedersdal M, Wulf HC. Evidence Based review of hair removal using laser and light source.J Eur Acad dermatol Venereol 2006; 20:9-20.

10. Rao J, Goldman MP. Prospective, comparative evaluation of three laser systems used individually and in combination for axillary hair removal. Dermatol Surg 2005; 31(12):1671-6; discussion 1677.

11. Rao K, Sankar TK. Long-pulsed Nd: YAG laser-assisted hair removal in Fitzpatrick skin types IV-VI. Lasers in Medical Science 2011; 26(5):623-6.

12. Watts J. Understanding the causes and management of hirsutism. Nurs Times 2006; 102:26-8.

13. Sanchez LA, Perez M, Azziz R. Laser hair reduction in the hirsute patient: A critical assessment. Hum Reprod Update 2002; 8:169-81.
14. Lorenz S, Brunnber S, Landthaler M et al. Hair removal with the long-pulsed Nd: YAG laser. A Prospective study with one year follow up. Lasers Surg Med 2002; 30:127-34.

15. Littler CM. Hair removal using an Nd: YAG laser system. Dermatologic Clinics 1999; 17(2):401-30.

16. Puri N. Comparative study of diode laser versus neodymiumyttrium aluminum: Garnet laser versus intense pulsed light for the treatment of hirsutism. Journal of Cutaneous and Aesthetic Surgery 2015; 8(2):97.

17. Shrimal A, Sardar S, Roychoudhury S et al. Long-pulsed Nd: YAG laser and intense pulse light-755 $\mathrm{nm}$ for idiopathic facial hirsutism: A comparative study. Journal of Cutaneous and Aesthetic Surgery 2017; 10(1):40.

18. Kamal T. Long-pulsed Nd:YAG laser and intense pulse light therapy for idiopathic facial hirsutism. A comparative study. J Pak Assoc Dermatol 2006; 16:205-9.

19. Tanzi El, Alster TS. Long-pulsed 1064 nm Nd: YAG laser-assisted hair removal in all skin types. Dermatol Surg 2004; 30:13-7.

20. Goldberg DJ, Silapunt S. Hair Removal using a long pulsed Nd: YAG Laser: Comparison at fluences of $50.80 .100 \mathrm{~J} / \mathrm{cm}^{2}$.Dermatol Surg 2001; 27:434-6.

21. Mittal R, Sriram S, Sandhu K. Evaluation of long-pulsed $1064 \mathrm{~nm}$ $\mathrm{Nd}$ : YAG laser-assisted hair removal vs multiple treatment sessions and different hair types in Indian patients. Journal of Cutaneous and Aesthetic Surgery 2008; 1(2):75. 